\title{
VEGETATION MAPPING OF A COASTAL DUNE COMPLEX USING MULTISPECTRAL IMAGERY ACQUIRED FROM AN UNMANNED AERIAL SYSTEM
}

\author{
C. Suo ${ }^{1, *}$, E. McGovern ${ }^{1}$, A. Gilmer ${ }^{2}$ \\ ${ }^{1}$ School of Surveying and Construction Management, Dublin Institute Technology, Dublin, Ireland - (d15123973@mydit.ie; \\ eugene.mcgovern@dit.ie) \\ ${ }^{2}$ Environmental Sustainability \& Health Institute, Dublin Institute Technology, Dublin, Ireland - alan.gilmer@dit.ie
}

\section{Commission I, ICWG I/II}

KEY WORDS: Vegetation Mapping, Unmanned Aerial Systems, Multispectral Sensor.

\begin{abstract}
:
Vegetation mapping, identifying the distribution of plant species, is important for analysing vegetation dynamics, quantifying spatial patterns of vegetation evolution, analysing the effects of environment changes on vegetation, and predicting spatial patterns of species diversity. Such analysis can contribute to the development of targeted land management actions that maintain biodiversity and ecological functions. This paper represents a methodology for 3D vegetation mapping of a coastal dune complex using a multispectral camera mounted on an Unmanned Aerial System (UAS) with particular reference to the Buckroney dune complex in Co. Wicklow, Ireland. UAS, also known as Unmanned Aerial Vehicles (UAV's) or drones, have enabled high-resolution and highaccuracy ground-based data to be gathered quickly and easily on-site. The Sequoia multispectral camera used in this study has green, red, red-edge and near infrared wavebands, and a normal RGB camera, to capture both visible and NIR images of the land surface. The workflow of 3D vegetation mapping of the study site included establishing ground control points, planning the flight mission and camera parameters, acquiring the imagery, processing the image data and performing features classification. The data processing outcomes include an orthomosiac model, a 3D surface model and multispectral images of the study site, in the Irish Transverse Mercator coordinate system, with a planimetric resolution of $0.024 \mathrm{~m}$ and a georeferenced Root-Mean-Square (RMS) error of 0.111 $\mathrm{m}$. There were 235 sample area $(1 \mathrm{~m} \times 1 \mathrm{~m})$ used for the accuracy assessment of the classification of the vegetation mapping. Feature classification was conducted using three different classification strategies to examine the efficiency of multispectral sensor data for vegetation mapping. Vegetation type classification accuracies ranged from $60 \%$ to $70 \%$. This research illustrates the efficiency of data collection at Buckroney dune complex and the high-accuracy and high-resolution of the vegetation mapping of the site using a multispectral sensor mounted on UAS.
\end{abstract}

\section{INTRODUCTION}

Coastal dune fields are at the transition between terrestrial and marine ecosystems which are highly-valued, natural resources for providing drinking water, mineral resources, recreation, ecoservices and desirable land for housing development (Frosini et al., 2012). These natural resources provide food and habitation for aquatic and terrestrial organisms and also offer human settlement and recreation spaces as well. Activities at the coastal zone area can contribute to local and national economic development, in areas like aquaculture, fisheries and tourism, and the area also has an important function to control erosion and flooding thus protecting and maintaining environmental development (Fenu et al., 2012). In recent years, increasing tourism and development in the coastal dune area of the South East of Ireland have resulted in increased pressure on the environment, resulting in issues including soil erosion, flooding and habitat loss (Mckenna et al., 2007).

A high-resolution vegetation map across a coastal dune complex, with accurate distribution and population estimates of different functional plant species, can be used to analyse vegetation dynamics, quantify spatial patterns of vegetation evolution, analyse the effect of environmental changes on vegetation, and predict spatial patterns of species diversity (Vaca et al., 2011). These can contribute to the development of targeted land management actions that maintain biodiversity and ecological functions.
Researchers have used remote sensing data to create vegetation maps. Vogelman and Rock (1986) used Thematic Mapper data to characterize the decline tendency of plants. Eder (1989) used autumn aerial photography to help distinguish deciduous vegetation species. Schriever and Congalton (1995) presented the method of using multi-seasonal TM data for vegetation mapping in New Hampshire and the result showed that October imagery could improve classification accuracy. Reese et al. (2002) created vegetation maps at national scale and used multiseasonal data to improve the accuracy of classification. DeGIoria et al., 2001 and Laba et al., 2002 used enhanced and multi-temporal satellite data for regional land cover mapping associated with the USGS Gap Analysis Project. There is a concern about the resolution of these vegetation maps created by using remote sensing data from National Mapping Agencies (Hartley et al., 2004). Some environmental variability was lost because of coarse resolution and reduced the accuracy of vegetation classification (Hijmans et al., 2005; Zerbe, 1998).

A single dune complex is often represented as a long and narrow strip because conventional remote sensing maps are often produced at national and regional scales (Acosta et al., 2005). It is quite difficult to generate vegetation maps with accurate and detailed land cover information for a small coastal dune complex. Light Detection and Ranging (LiDAR) provided an option for generating Digital Terrain Models (DTM) and Digital Surface Models (DSM) even for a small target area (Bolivar et al., 1995; Crapoulet et al., 2016). A 1-2 m spatial resolution of LiDAR dataset was considered sufficient to study 
volumetric change of a coastal dune complex in North Carolina. (Woolard and Colby, 2002).

Relatively new remote sensing platforms, knowns as Unmanned Aerial Systems (UAS), UAV (Unmanned Aerial Vehicles), RPAS (Remotely Piloted Aircraft System), "Aerial Robots" or simply "drones", are now available for on-site data acquisition (Turner et al. 2016). In comparison of other remote sensing platforms, UAS typically has a lower operating height which enables the collection of higher spatial resolution in a small area (Venturi et al., 2016). UAS also has flexible revisit times whereas the availability of other remote sensing data is limited in acquisition date and coverage depending on national commission. It also provides the possibility for data acquisition at inaccessible areas or hazardous environments.

Importantly, Structure from Motion (SfM), for UAS-collected data processing, is a technique that has emerged in the last decade to construct the photogrammetry-based 3D models (Tonkin and Midgley, 2016). The critical element for implementation of photogrammetry to 3D mapping using SfM is the collection of numerous overlapping images of the study area (Uysal et al. 2015). From each pair of overlapping pictures, SfM can calculate the unique coordinate position $(x, y, z$ or Easting, Northing, Elevation) of a set of particular points presented in both images. To maintain the accuracy of the mapping, the overlapping area for each two images should be at least $60 \%$, ensuring sufficient shared points can be recognised by software for the map construction. To generate a 3D model, many thousands of matching object and textural features are automatically detected in multiple overlapping images of the ground surface, from which a high density point cloud with 3D coordinate positions is derived.

A multispectral camera mounted on a UAS allows both visible and multispectral imagery to be captured that can be used for characterizing land features, vegetation health and function. The Sequoia multispectral sensor has green $(530-570 \mathrm{~nm})$, red $(640-680 \mathrm{~nm})$, red edge $(730-740 \mathrm{~nm})$ and near infrared $(770-$ $810 \mathrm{~nm}$ ) wavebands and a RGB camera (400 nm to $700 \mathrm{~nm}$ ) (Ren et al., 2017). Colour, structure and surface texture of different land features can influence the reflectance pattern of the wavebands (Fernández-Guisuraga et al., 2018). By analysing these different spectral reflectance patterns, different earth surface features can be identified. Normalized differential vegetation index (NDVI), which relates the reflectance of land feature at Near Infrared and red wavebands, is widely used to differentiate green vegetation areas from other land features, such as water and soil (Gini et al., 2012). The index range from -1 to 1 , with 0 representing the approximate value of no vegetation (Silleos et al., 2006).

This research generated 3D vegetation mapping of a coastal dune complex using a multispectral sensor mounted on a UAS with particular reference to the Buckroney dune complex in Co. Wicklow, Ireland. It presents a workflow for 3D vegetation mapping of a coastal dune complex, including establishing ground control points (GCPs), planning the flight mission and camera parameters, acquiring the imagery, processing the image data and performing features classification. The process illustrates the efficiency of the image data collection and highresolution of the vegetation mapping of the site using a multispectral camera mounted on a UAS. However, classification accuracy need to be considered where O'Donoghue and Regan (2007) quote an overall classification accuracy of $65 \%$ as the minimum acceptable for reliable vegetation mapping. To examine the accuracy, classifications were conducted using three different band combination available within the Sequoia multispectral sensor:

1. Red + Green + Blue (RGB camera wavebands)

2. Green + Red + Red edge + NIR (Multispectral sensor wavebands)

3. Red + Green + Blue + Red edge + NIR (Multispectral wavebands plus Blue)

\section{STUDY SITE}

The Brittas-Buckroney dune complex (Figure 1) is located c. 10 $\mathrm{km}$ south of Wicklow town on the east coast of Ireland and comprises two main sand dune systems, viz. Brittas Bay and Buckroney Dunes (NPWS, 2013). The study site for this research is Buckroney Dunes, which is managed by the National Park \& Wildlife Service. The area of the Buckroney dune complex is c. 40 ha.

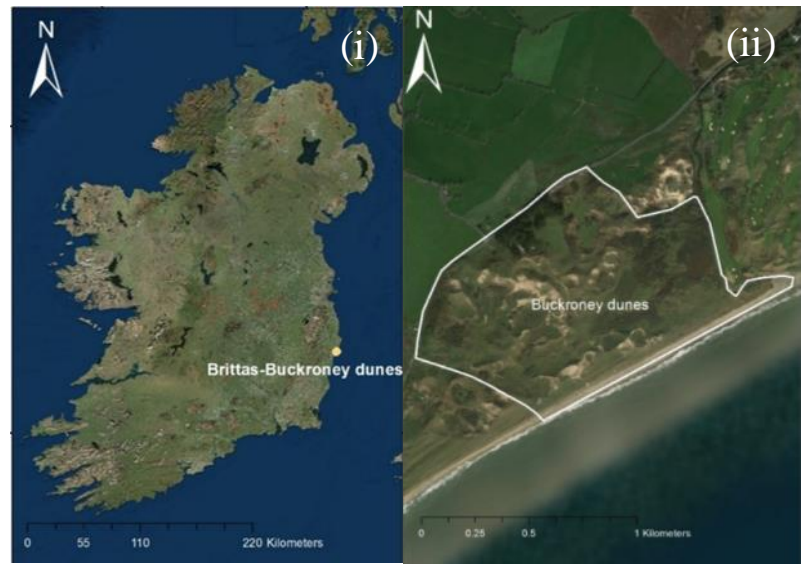

Figure 1. Study site (i) general location and (ii) site details.

Within this site, ten habitats listed on the EU Habitats Directive are present, including two priority habitats in Ireland, viz. fixed dune and decalcified dune heath (NPWS, 2013). This dune system also contains good examples of different dune types. At the northern part of Buckroney dune complex, there are some representative parabolic dunes, while embryonic dunes mostly occur at the southern part.

Meanwhile, the site is notable for the presence of welldeveloped plant communities (NPWS, 2013). Mosses occur frequently in this dune complex. Sharp Rush (Juncus acutus) dominates south of the inlet stream to the fen area at the eastern boundary of the site, and in small areas elsewhere within the dune complex. The main dune ridges are dominated by Marram (Ammophila arenaria). Gorse (Ulex europaeus) is also notable at the back of the dunes. To the west, a dense swamp of Common Reed (Phragmites australis) is present. There are also extensive areas of Rusty Willow (Salix cinerea subsp. oleifolia) scrub throughtout the dune complex.

With land acquisition in recent years, the marginal areas of the dune system have been reclaimed as farmland. The increasing anthropogenic activities at the dune system, such as farming and recreation activities, have brought pressure on the dune ecosystem development, with hazards like soil erosion, flooding and habitat loss. Accurate and high-resolution 3D vegetation mapping can contribute to an understanding of the natural processes at the coastal dune complex which can, in turn, help with the development of target land management policies. 


\section{METHODOLOGY}

The UAS platform was a DJI Phantom 3 Professional, which has 4 rotors, a central body containing the electronic components and landing gear that sustains the entire structure (Figure 2). It is powered by a lithium polymer battery that allows a flight time up to $25 \mathrm{~min}$. The multispectral sensor used in this study was a Parrot Sequoia which is comprised of five individual cameras and a sun sensor. The cameras consist of a 16 MP RGB camera and four 1.2 MP multispectral cameras that record in the green, red, red edge and near infrared wavebands. The camera cluster is mounted under the central body of the UAS and sun sensor positioned above the central body as seen in Figure 3.1. The field work of this study was conducted in February 2018.

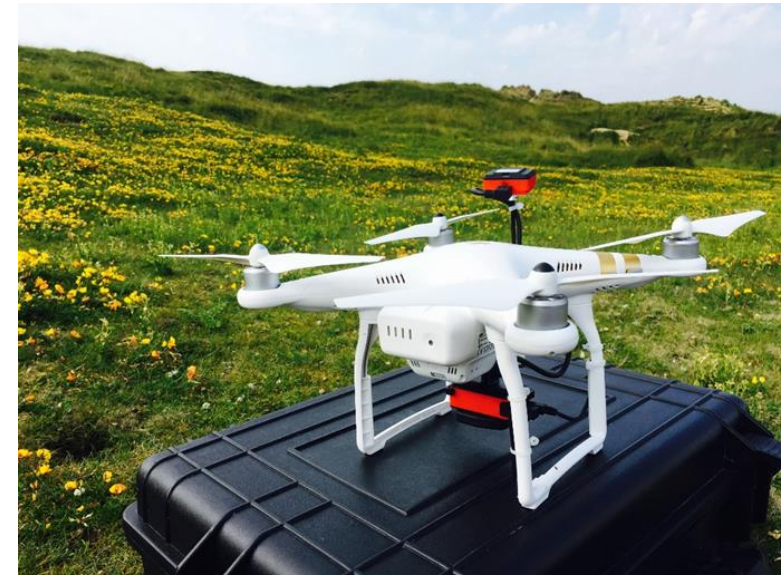

Figure 2. Sequoia multispectral sensor mounted on DJI UAS

\subsection{Ground Control Points}

The field surveying with the UAS started with establishing ground control points (GCPs) around the study site whose Irish Transverse Mercator (ITM) coordinates were determined using a Trimble R10 GNSS receiver connected to the Trimble VRS NRTK system (as seen in Figure 3). These GCPs were used at the processing stage to georeference the 3D models generated from the data. In this study, 20 GCPs marked as white crosses on-site, were recorded and were identifiable in the images captured by the UAS.

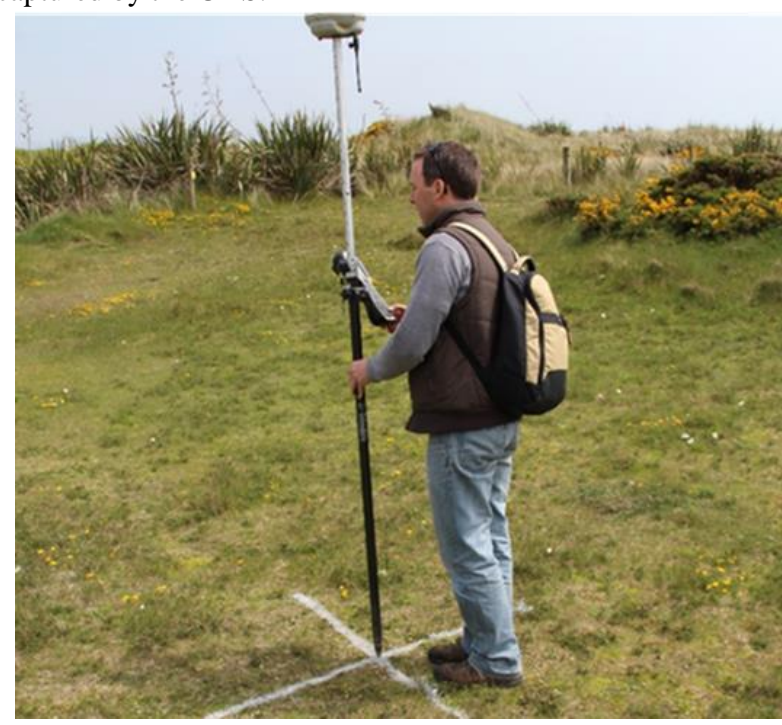

\subsection{Flight Mission Planning}

The Pix4DCapture software provides a solution for flightpath design for UAS surveying projects. For this study, parameters of flight mission were set as in Table 1 .

\begin{tabular}{|c|c|c|c|}
\hline \multicolumn{2}{|c|}{$\begin{array}{l}\text { UAS flight mission } \\
\text { parameters }\end{array}$} & \multicolumn{2}{|c|}{$\begin{array}{l}\text { Multispectral camera } \\
\text { captured parameters }\end{array}$} \\
\hline Flight height & $80 \mathrm{~m}$ & Capture mode & GPS \\
\hline $\begin{array}{l}\text { Overlapping alone } \\
\text { line }\end{array}$ & $80 \%$ & Interval distance & $15 \mathrm{~m}$ \\
\hline $\begin{array}{l}\text { Overlapping } \\
\text { between lines }\end{array}$ & $75 \%$ & $\begin{array}{l}\text { Image } \\
\text { resolution }\end{array}$ & $1.2 \mathrm{Mpx}$ \\
\hline $\begin{array}{l}\text { Estimated flight } \\
\text { time }\end{array}$ & $\begin{array}{l}10 \\
\min \end{array}$ & Bit depth & 10-bit \\
\hline
\end{tabular}

Table 1. Parameters set for UAS flight mission and multispectral camera

\subsection{Radiometric Calibration}

Radiometric calibration was required to convert the raw imagery data to absolute surface reflectance data thereby removing the influence of different flights, dates, and weather conditions. The collection of solar irradiance data for each flight is required for radiometric calibration. Image of a white balance card, captured before each flight, provided an accurate representation of the amount of light reaching the ground at the time of capture. The balance card containing a grey square and QR codes around it as shown in Figure 4. The large grey square in the centre of the balance card is a calibrated "panel" that can be used to calibrate the reflectance values as every balance card have been tested to determine its reflectance across the spectrum of light captured. The captured balance card images provided absolute reference information which can be applied to each image individually for the collection of repeatable reflectance data over different flights, dates, and weather conditions.

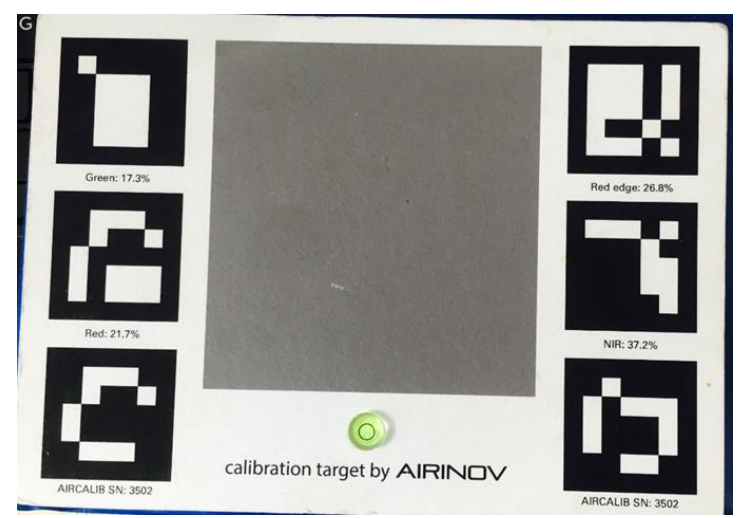

Figure 4 . The balance card used for radiometric calibration.

\subsection{Other Consideration}

After setting the flight parameters and reflectance calibration, a number of other were considered before launching the UAS. These included weather conditions, backup battery, SIM card for image storage and UAS controller, to ensure a safe and effectively flight. In case of an emergency, the flight could be terminated manually from the controller. In consideration of the $25 \mathrm{~min}$ battery life for a single flight of the UAS, the study site of about 40 ha was divided into four overlapping flying events.

Figure 3. GCPs set on site for RPAS surveying. 


\subsection{Data Processing}

Overlapping imagery data collected by the UAS was processed with Pix4D SfM software to generate geo-referenced orthomosaics, DSMs, contour lines, 3D point clouds and textured mesh models in various formats. As the image database of this research was very large, a powerful computer with enough storage was used to save the files. The processing procedure is highly automated but required over 70 hours for the whole study site. The RGB imagery and multispectral imagery were processed in two separate projects. The RGB project required GCP position information to refer the project in the ITM coordinate system. Images of calibration target were used for radiometric calibration and to remove the brightness difference in the multispectral bands project. Other processing options were customized to select the proper scale and format for the resulting data, including Initial Processing, Point Cloud and Mesh, DSM, orthomosaic and Index and Resources and Notification. A quality assessment report for each processing step was generated and stored.

\section{RESULTS AND ACCURACY ASSESSMENT}

\subsection{Data Processing Outcomes}

The data processing outcomes include 3D point clouds, orthomosaic model, and DEM which were created from RGB imagery, while NDVI index map and individual multispectral waveband models of the site were generated from collected multispectral imagery. These results were all in reference to the ITM grid coordinate system. Outcomes from RGB imagery had a spatial resolution of $0.024 \mathrm{~m}$ and a georeferenced Root-MeanSquare (RMS) error of $0.111 \mathrm{~m}$, while outcomes from multispectral imagery had a spatial resolution of $0.096 \mathrm{~m}$ and the error from GCPs as check points was $0.798 \mathrm{~m}$.

The orthomosaic model of the site is shown in Figure 5, which shows that relatively high spatial resolution is sufficient to distinguish land features, such as road, sand, grass land and bush land.

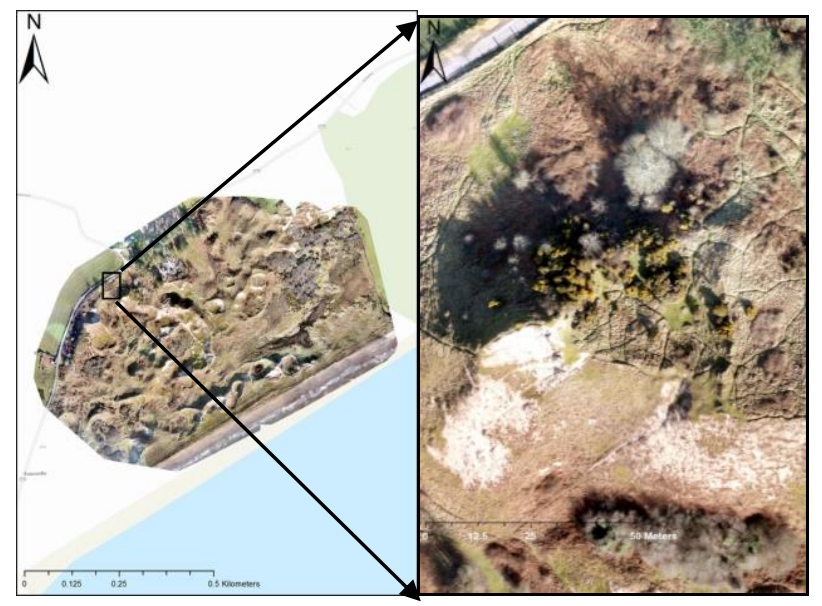

Figure 5. Orthomosaic model of study site and the detail of a selected area.

The DEM represents the elevation changes over the dune complex. In Figure 6, red represent the higher elevation areas and blue represents the relatively lower elevation areas. The elevation range is from $-10.7 \mathrm{~m}$ to $26.0 \mathrm{~m}$ against mean sea level.

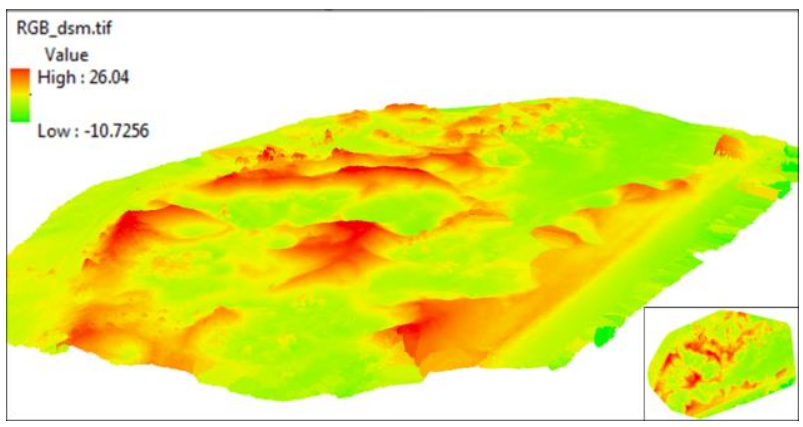

Figure 6. DEM of study site as vertical view and oblique view.

The NDVI map in Figure 7 shows the index value variation over the study site. A detail NDVI map of the same area as the orthomosaic, provides a clear representation of different land features. The index of road area was -0.1 , while the bush area has index about 0.85 . This map is useful to distinguish nonvegetation and vegetation features as the index value of nonvegetation features is below 0 while index value of vegetation feature is over 0 .

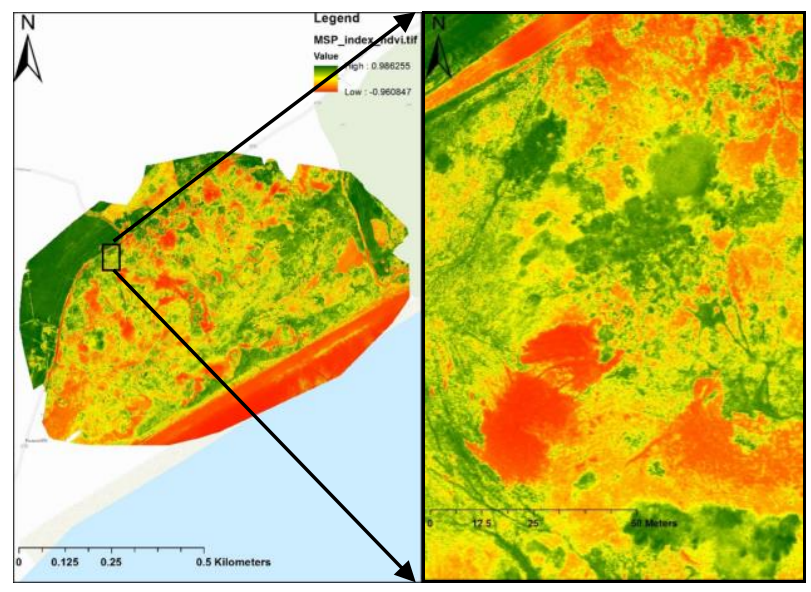

Figure 7. NDVI index map and the details in the selected area.

\subsection{Accuracy Assessment}

Within the high-resolution orthomosaic model (Figure 5), different land cover features and vegetation areas, including Pasture, Rusty Willow, Gorse, Sharp Rush, Marram, Common Reed and Mosses, were clearly presented. To examine the efficacy of the Sequoia multispectral sensor for vegetation mapping, semi-automatic classifications were conducted based on three data combination strategies:

1. Red + Green + Blue (RGB camera wavebands)

2. Green + Red + Red edge + NIR (Sequoia multispectral sensor wavebands)

3. Red + Green + Blue + Red edge + NIR (Sequoia multispectral sensor wavebands plus the blue layer from the RGB camera)

Based on the orthomosaic map shown in Figure 5, $1 \mathrm{~m} \times 1 \mathrm{~m}$ ground truth samples were selected for classification to 12 different land features which represent the significant land cover types on the site. These were seven dominant vegetation land features (Pasture, Rusty Willow, Gorse, Sharp Rush, Marram, Common Reed and Mosses) and other land cover features, viz. road, beach, stream, sand and built area. 
There were 280 samples identified for ground truth information. Forty-five ground truth samples among 280 were used as signature files for a supervised classification using the Maximum Likelihood Classification (MLC) algorithm. Three classification strategies were applied using same training samples and same ground truth samples as check samples for accuracy assessment. A classified vegetation map is presented in Figure 8. By comparing the ground truth information and classified information in the remaining 235 samples, the overall accuracies of the three classification strategies were calculated as $68.5,59.9 \%$ and $69.8 \%$ respectively. The third classification strategy, which used the four multispectral sensor wavebands plus blue, resulted in higher classification accuracy in vegetation mapping.

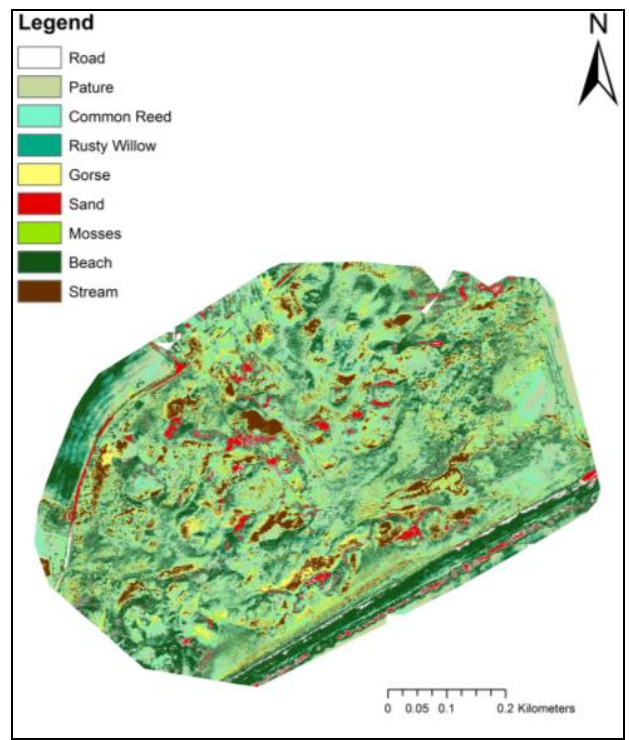

Figure 8. Vegetation mapping of Buckroney dune complex using third classification strategy $($ Red + Green + Blue + Red edge + NIR).

\subsection{Discussion}

The third classification strategy used more wavebands in combination for classification which considered more wavebands reflectance patterns as reference information to increase the characteristics of each land features and improve the accuracy of identification. This may causes the higher accuracy in third classification as it containing more wavebands.

The classification accuracy of different classification strategies may also be influenced by the imagery resolution. The RGB camera and multispectral sensor have different resolutions, being 16MP and 1.2 MP respectively. This may lead to the classification accuracy of 4 wavebands combination of multispectral sensor being lower than the 3 wavebands combination of RGB camera.

In addition, the RGB camera contains three non-discrete spectral bands, whereas the multispectral sensor has four discrete spectral bands. As seen in Figure 9, non-discrete spectral bands has a distinctly curved response and each band has considerable overlap in the wavelength range, while the discrete spectral bands have an even respond without overlap. This result in the multispectral wavebands providing more reliable reflectance pattern of land features.
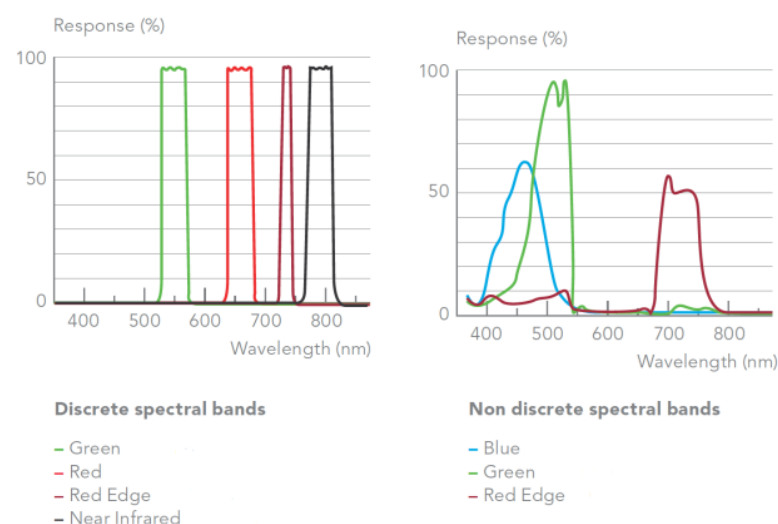

Figure 9. Wavelength and response of discrete and non-discrete spectral bands (Micasense, 2018)

\section{CONCLUSION}

High-resolution vegetation mapping was successfully generated from the imagery captured using a multispectral sensor mounted on a UAS. Classification accuracy using four Sequoia multispectral wavebands combination is lower than the accuracy using three wavebands combination of RGB camera. The highest classification accuracy was achieved using a five wavebands combination which were Sequoia multispectral sensor wavebands plus the blue layer from the RGB camera. Captured imagery resolution, number of wavebands for combination and bands discretion may be the reasons for different classification accuracy using different classification strategies.

This research also highlights an effective option for on-site surveying, significantly reducing the hazard and workload for the development of vegetation maps and DEM's of a study area. Using the multispectral sensor resulted in data captured from a wider range of wavebands than RGB camera, with better resolution and accuracy than other conventional remote sensing technologies, enabling the generation of dense 3D point clouds by SfM, and orthormosaic models, DEM and NDVI index map. In these maps, vegetation distribution and elevation changes over the Buckroney dune complex were represented clearly. The classification result also illustrated the high accuracy achieved for identifying different land feature areas based on these maps.

However, notwithstanding the many benefits and advantages of UAS and multispectral technology in vegetation mapping, the technology still has some challenges with dune complex surveying. One issue is the permission, licensing, training required and restrictions to areas of UAS flight from the relevant Aviation Authority. As different countries have varying legislation controlling UAS use, it is recommended to be wellinformed about the significant use limitations of UAS use before the start of any UAS project. Although the use of a UAS platform can save much time at the on-site data collecting stage, a considerable amount of time is required for data processing. Compared to other conventional survey methods, UAS is less robust as it is limited by environmental factors such as wind, precipitation and low light. 


\section{ACKNOWLEDGEMENTS}

This work funded by Fiosraigh scholarship programme in Dublin Institute Technology. The authors wish to acknowledge Ronan Hogan for assistance in data collection in the field work.

\section{REFERENCES}

Acosta A., Carranza M.L., Izzi, C.F. 2005. Combining land cover mapping of coastal dunes with vegetation analysis. Applied Vegetation Science, 8, 133-138.

Bolivar L., Carter W., Shrestha R. 1995. Airborne laser swath mapping aids in assessing storm damage. Florida Engineering, 26-27.

Crapoulet A., Héquette A., Levoy F., Bretel P. 2016. Using LiDAR Topographic Data for Identifying Coastal Areas of Northern France Vulnerable to Sea-Level Rise. Journal of Coastal Research, 75, 1067-1071.

DeGloria S.D., Laba M.L., Gregory S.K. 2001. Mapping the State of New York from Landsat TM. GIM International, 15(2), 76-79.

Eder J.J. 1989. Don't shoot unless it's autumn. Journal of Forestry, 87(6), 50-51.

Fenu G., Cogoni D., Ferrara C., Pinna M.S., Bacchetta G. 2012. Relationships between coastal sand dune properties and plant community distribution: The case of Is Arenas (Sardinia). Plant Biosystems, 146(3), 586-602.

Fernández-Guisuraga J.M., Sanz-Ablanedo E., Suárez-Seoane S., Calvo L. 2018. Using Unmanned Aerial Vehicles in Postfire Vegetation Survey Campaigns through Large and Heterogeneous Areas: Opportunities and Challenges. Sensors, 18(2), 1-17.

Frosini S., Lardicci C., Balestri E. 2012. Global Change and Response of Coastal Dune Plants to the Combined Effects of Increased Sand Accretion (Burial) and Nutrient Availability. PLOS ONE, 7(10), e47561.

Gini R., Passoni D., Pinto L. Sona G. 2012. Aerial images from an UAV system: $3 \mathrm{~d}$ modeling and tree species classification in a park area. Int. Arch. Photogram. Remote Sensing Spatial Information Science, 39(B1), 361-6.

Hartley S., Kunin W.E., Lennon J.J., Pocock M.J. 2004. Coherence and discontinuity in the scaling of specie's distribution patterns. Proceedings of The Royal Society, Biological Sciences, 271, 81-88.

Hijmans R.J., Cameron S.E., Parra J.L., Jones P.G., Jarvis A. 2005. Very high resolution interpolated climate surfaces for global land areas. International Journal of Climatology, 25, 1965-1978.

Laba M.L., Gregory S., Braden J., Ogurcak D., Hill E., Fegraus E., Fiore J., DeGloria S.D. 2002. Conventional and fuzzy accuracy assessment of the New York Gap Analysis Project land cover map. Remote Sensing of Environment, 82, 443-456.

McKenna J., O’Hagan A.M., Power J., Macleod M., Cooper A. 2007. Coastal dune conservation on an Irish commonage:
Community-based management or tragedy of the commons. The Geographical Journal, 173(2), 157-169.

MicaSense, 2018. What spectral bands does the Sequoia camera capture? MicaSense Knowledge Base site. https://support.micasense.com/hc/en-us/articles/217112037What-spectral-bands-does-the-Sequoia-camera-captur

National Parks \& Wildlife Service (NPWS), 2013. Site Synopsis: Buckroney-Brittas Dunes and Fen SAC. NPWS site documents 000729_Rev13.Doc. https://www.npws.ie/protectedsites/sac/000729

O'Donoghue B. and Regan L. 2007. Accuracy Assessment: Cowpens National Battlefield Vegetation Map. NatureServe: Durham, North Carolina.

Reese H.M., Lillesand T.M., Nagel D.E., Stewart J.S., Goldman R.A., Simmons T.E., Chipman J.W., Tessar P.A. 2002. Statewide land cover derived from multiseasonal Landsat TM data: A retrospective of the WISCLAND project. Remote Sensing of Environment, 82, 224-237.

Ren X., Sun M., Zhang X., Liu L. 2017. A Simplified Method for UAV Multispectral Images Mosaicking. Remote Sensing, 9(9), 1-21.

Schriever J.R., and Congalton R.G. 1995. Evaluating seasonal variability as an aid to cover-type mapping from Landsat Thematic Mapper data in the northcast. Photogrammetric Engineering and Remote Sensing, 61(3), 321-327.

Silleos N.G., Alexandridis T.K., Gitas I.Z. Perakis K. 2006, Vegetation indices: advances made in biomass estimation and vegetation monitoring in the last 30 years. Geocarto International, 21(4), 21-8.

Turner I.L., Harley M.D., Drummond C.D. 2016. UAVs for coastal surveying, Coastal Engineering, 114, 19-24.

Tonkin T.N. and Midgley N.G. 2016. Ground-control networks for image based surface reconstruction: an investigation of optimum survey designs using UAV derived imagery and structure-from-motion photogrammetry, Remote Sensing, 8(9), 786 .

Uysal M., Toprak A.S., Polat N. 2015. DEM generation with UAV Photogrammetry and accuracy analysis in Sahitler hill, Measurement, 73, 539-543.

Vaca R.A. Golicher D.J., Cayuela L. 2011. Using climatically based random forests to downscale coarse-grained potential natural vegetation maps in tropical Mexico. Applied Vegetation Science, 14, 388-401.

Venturi S., Di Francesco S., Materazzi F., Manciola P. 2016. Unmanned aerial vehicles and Geographical Information System integrated analysis of vegetation in Trasimeno Lake, Italy. Lakes and Reservoirs: Research and Management, 21, 519.

Vogelman J.E. and Rock B.R. 1986. Assessing forest decline in coniferous forests of Vermont using NS-001 Thematic Mapper data. International Journal of Remote Sensing, 7(10), 13031321. 
The International Archives of the Photogrammetry, Remote Sensing and Spatial Information Sciences, Volume XLII-1, 2018

ISPRS TC I Mid-term Symposium “Innovative Sensing - From Sensors to Methods and Applications", 10-12 October 2018, Karlsruhe, Germany

Woolard J.W. and Colby J.D. 2002. Spatial characterization, resolution, and volumetric change of coastal dunes using airborne LIDAR: Cape Hatteras, North Carolina, Geomorphology, 48, 269-287.

Zerbe S. 1998. Potential natural vegetation: validity and applicability in landscape planning and nature conservation. Applied Vegetation Science, 1, 165-172. 